Original article

Central Eur J Paed 2017;13(1):46-54.

DOI $10.5457 / \mathrm{p} 2005-114.169$

\title{
IMPACT OF IMMUNIZATION ON EPIDEMIOLOGY OF VACCINE- PREVENTABLE DISEASES IN THE FEDERATION OF BOSNIA AND HERZEGOVINA
}

\author{
Institute of Public Health of \\ Federation Bosnia and Herzegovina \\ Correspondence: \\ sanjinm@yahoo.com \\ Tel.: + 38733564634 \\ Fax.: + 38733564632
}

Sanjin MUSA, Mirsada MULAOMEROVIĆ

Received: November 13, 2016

Accepted: February 13, 2017

Key words: Vaccine-preventable diseases $~$ Immunization • Outbreaks.

\begin{abstract}
Objective - The aim of this study is to summarize the epidemiology of vaccine preventable diseases in the Federation of Bosnia and Herzegovina from 1996 to 2015, and assess the impact of immunization. Methods - The analyses presented in this paper are based on the data collected by the Institute for Public Health of the Federation Bosnia and Herzegovina or by reviews of historical data. Results - Data suggests clear evidence of the reduction of burden of vaccine-preventable diseases after introduction of vaccines in the immunization program. Diphtheria and poliomyelitis have been eliminated, and tetanus and pertussis have been significantly reduced. Since the target of $95 \%$ vaccination coverage against measles, mumps and rubella was not achieved and the number of susceptible individuals' increased, infectious agents still circulates and delayed outbreaks occur. Conclusion Despite impressive achievements in vaccine-preventable diseases control, continued trust and investments in the immunization program in the Federation of Bosnia and Herzegovina are essential.
\end{abstract}

\section{Introduction}

Immunization is one of the most important health interventions, with an impact on incidence and then on complications/hospitalizations and deaths due to infectious diseases. Every year, over 100 million children are immunized worldwide (1). In the People's Republic of Bosnia and Herzegovina (BA), as a part of the former Yugoslavia, vaccination against tetanus was introduced in 1946 (2), followed by vaccination against tuberculosis and diphtheria in 1948, and by vaccination against poliomyelitis and pertussis in 1961 (as a combined DTP vaccine) $(3,4,5,6)$.

In 1974 the World Health Organization (WHO), based on the success of the smallpox program, established the Expanded Program in
Immunization (EPI), with initial goals to ensure that every child received protection against six childhood diseases (tuberculosis, polio, diphtheria, pertussis, tetanus and measles) by the time they were one year of age (7). Measles vaccination has been compulsory in BA since 1970 (8). In 1981, measles-mumps-rubella (MMR) vaccine was included in the schedule for all infants of 12-14 months of age (9). Since 2001 two MMR doses have been scheduled at 12-18 months and 7 years (or at the first grade of primary school, after moved at 6 years) (10).

During the war that took place in BA in early 1990s, even basic childhood vaccinations were affected. After the Dayton Peace Agreement was signed in 1995, the constitution of BA (an integral part of the Agree- 
ment) defined a complex political and administrative structure of the state. It gave the mandate for organization, funding and provision of health services to two entities, the Federation of BA and the Republic of Srpska, as well as the Brčko District of BA (11).

Recent decades brought the introduction of newly developed vaccines in the immunization programs, such as the vaccine against hepatitis B and Haemophylus influenzae type b. However, they also brought new challenges. Challenges of vaccine procurement in the open market (local production has been stopped or not well adapted to new situation), reinforced anti-vaccination sentiments in media and vaccine hesitancy are major factors influencing implementation of immunization program.

The immunization program in the Federation of $\mathrm{BA}$ includes mandatory vaccination against 10 infectious diseases: tuberculosis, diphtheria, pertussis, tetanus, poliomyelitis, measles, mumps, rubella (including congenital rubella syndrome), invasive Haemophilus influenzae type b (Hib) and hepatitis B.

The current immunization schedule is given in the Table 1. Acellular pertussis was introduced in the immunization program in 2003 for booster doses, and in 2008 (September) for primary series. Since 2004 , booster dose in second year of age was excluded from the schedule.
In 2015, due to shortage of a combined vaccines containing acellular pertussis, DTaP-IPV (diphtheria, tetanus, acellular pertussis, inactive polio) vaccine was replaced with DTwP (diphtheria, tetanus, whole cell pertussis) and oral polio vaccines. The estimated birth cohort in 2015 was 20422 .

In this study, we will summarize the epidemiology of vaccine preventable diseases in the Federation of BA from 1996 to 2015, and assess the impact of immunization. Tuberculosis, invasive $\mathrm{Hib}$, and hepatitis $\mathrm{B}$ are not covered in this study, since assessing the effects of the vaccine against these diseases requires: a different approach in assessment of effects of BCG as an intervention against severe childhood tuberculosis, improved laboratory capacity for invasive Hib, and longer period for the assessment of impact of hepatitis $B$ vaccine.

\section{Methods}

The data presented in this paper are collected by the Institute for Public Health of the Federation $\mathrm{BA}$, through the passive surveillance system or by listing of historical reports.

According to the Law on Protection of Population against Communicable Diseases of the Federation of BA (12) and Rulebook on Manner of Reporting of Communicable Diseases (13), all health care providers in Fed-

Table 1 Immunization schedule in the Federation of Bosnia and Herzegovina

\begin{tabular}{lllllllllll}
\hline \multirow{2}{*}{ Birth } & Months & \multicolumn{10}{c}{ Years } \\
\cline { 2 - 10 } & 1 & 2 & 4 & 6 & 12 & 18 & 5 & 6 & 14 & 18 \\
\hline BCG & - & - & - & - & - & - & - & - & - & - \\
\hline HepB & HepB & - & - & HepB & - & - & - & - & - & - \\
\hline- & - & DTaP-IPV & DTaP-IPV & DTaP-IPV & - & - & DTaP-IPV & - & dT & TT \\
\hline- & - & Hib & Hib & - & - & Hib & - & - & - & - \\
\hline- & - & - & - & - & - & OPV & - & & OPV & - \\
\hline- & - & - & - & - & MMR & & - & MMR & - & - \\
\hline
\end{tabular}

BCG=Bacille Calmette-Guerin (vaccine against tuberculosis); HepB=hepatitis B vaccine; DTaP-IPV=Diphtheria, tetanus, acellular pertussis and inactivated polio vaccine; $\mathrm{dT}=$ Diphtheria and tetanus vaccine for adults; TT=Tetanus vaccine; Hib=Haemophilus influenzae type $\mathrm{B}$ vaccine; $\mathrm{OPV}=\mathrm{Oral}$ polio vaccine; $\mathrm{MMR}=$ Measles, mumps and rubella vaccine. 
eration of BA who diagnose a communicable disease from the list of reportable diseases are obliged to report it on a standardized form to a local epidemiology unit, according to the place of residence of the patient. A local epidemiologist is responsible for collecting and reporting data and conducting an epidemiological investigation following a report. Provider's data are aggregated and analyzed within local, cantonal and federal administrative levels.

Information on vaccination coverage is also regulated by the Law on Protection of Population against Communicable Diseases of the Federation of BA (12) and the Rulebook on Manner of Conducting Mandatory Immunization, Immunoprophylaxis and Chemoprophylaxis against Communicable Diseases and Persons that are Subject to such Obligation (14). Data is collected and analyzed at the local, cantonal and federal level, on a monthly, quarterly, semi-annually and annually basis. Immunization registries are still paper-based. Vaccine coverage is assessed in one to two-year-old children (for MMR), or in older groups of children for booster doses, using administrative methods.

\section{Results}

During the period 1996-2015, immunization coverage (Fig. 1-6) with different vaccines was mostly between $80-90 \%$ [DTP3 range $75 \%$ (2015) - 95\% (1999); MMR1 range $77.9 \%(2015)-96.2 \%$ (2007)]. In 2015 , due to shortage of a combined vaccine with acellular pertussis and replacement with whole cell pertussis vaccine, coverage less than $80 \%$ was registered. In recent years antivaccine lobbyists have been present, who vocalize their opinions against the safety of vaccine, mostly using Internet for their activism, but also interacting with mainstream media.

From the year 1996 to 2015, cases of measles, mumps and rubella were regularly reported. Large outbreaks of measles were registered in 1997/98 and 2014/15, with 6748 and 5103 reported cases. In the 2014/15 outbreak, 64.98\% (3316) cases of measles were among the unvaccinated, $8.4 \%$ (427) among the under-vaccinated, and 2.3\% (115) among fully vaccinated. For $24.4 \%$ (1245) there was no date on the immunization status. In 2014, measles case-based surveillance became operational in BA. In total, through this surveillance system, 553 hospitalized cases of measles were reported. There is a need for the further improvement of this surveillance system. In one case a pregnant woman, who developed measles with pneumonia, delivered a premature infant (in $27^{\text {th }}$ week) who died a couple of days later.

An increased number of mumps cases was reported during the 1999-2002 period. In late 2010, an outbreak of mumps occurred and lasted until the end of 2012, with 8072 reported cases. Among the reported cases (based on immunization status): $39.0 \%$ (3151) were unvaccinated, $15.7 \%$ (1264) were under-vaccinated, $15.3 \%$ (1239) were fully vaccinated and for $29.96 \%$ (2418) there were no data on the immunization status.

In the study by Hukić et al. (15), 105 patients hospitalized at the Clinical Centre of the University of Sarajevo between April 2011 and September 2012 were described. The great majority was male $(81 \%)$. The medical records documented serious complications such as orchitis in $60 \%$ of all males, meningitis in $9 \%$ of all males and orchitis and meningitis in $2 \%$ of all males.

Like measles and mumps, in late 1990's an increased number of rubella cases were registered. During the 2009/2010 outbreak of rubella there were 2084 registered cases. Among these cases there were four pregnant women. In 2010, among 2018 reported cases of rubella, $61.6 \%$ were unvaccinated, $11.2 \%$ were under-vaccinated, and $6.5 \%$ were fully vaccinated. For $20.6 \%$ cases there were no data on the immunization status. 
In the Federation of BA, one-year-old children are routinely immunized with MMR, with a second dose at age six. During the period of 1996-2015, the $95 \%$ target for vaccination coverage with the first dose of the MMR vaccine was achieved only in the year 2007. The MMR coverage was mostly under $90 \%$ for vaccination coverage (Fig. 1).

As an example of the impact of vaccination against measles, we compare incidence of measles and varicella during the period 1996-2015. Vaccination against varicella is not included in the immunization schedule. Both diseases are viral, spread by the same respiratory route, with a high basic reproduction number. There is a clear decrease in measles incidence compared to varicella (Fig.
4). BA is a country with endemic measles and rubella transmission. Because the target of $95 \%$ vaccinated against measles was not achieved and the number of susceptible individual's increased, infectious agents still circulates and delayed outbreaks occur.

In the Federation of BA during the last 20 years, 17 cases of tetanus were registered. Data on age group were not available in the first years after the war. Among 10 registered tetanus cases during 2000-2015, 60\% were over 30 years old.

Pertussis is an acute respiratory tract infection, caused by Bordetella pertussis, and is characterized by intense coughing. Pertussis is a life-treating disease in infants and young children. In the Federation of BA, 802 cases

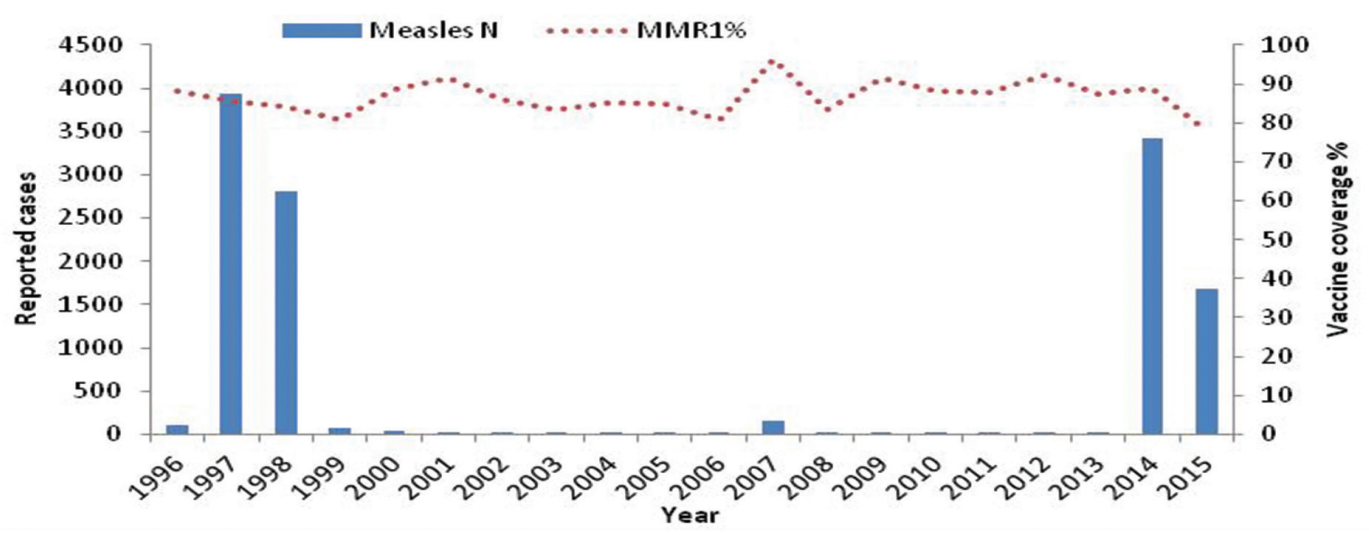

Fig. 1 Annual reported cases of measles and MMR1 coverage, Federation Bosnia and Herzegovina 1996-2015.

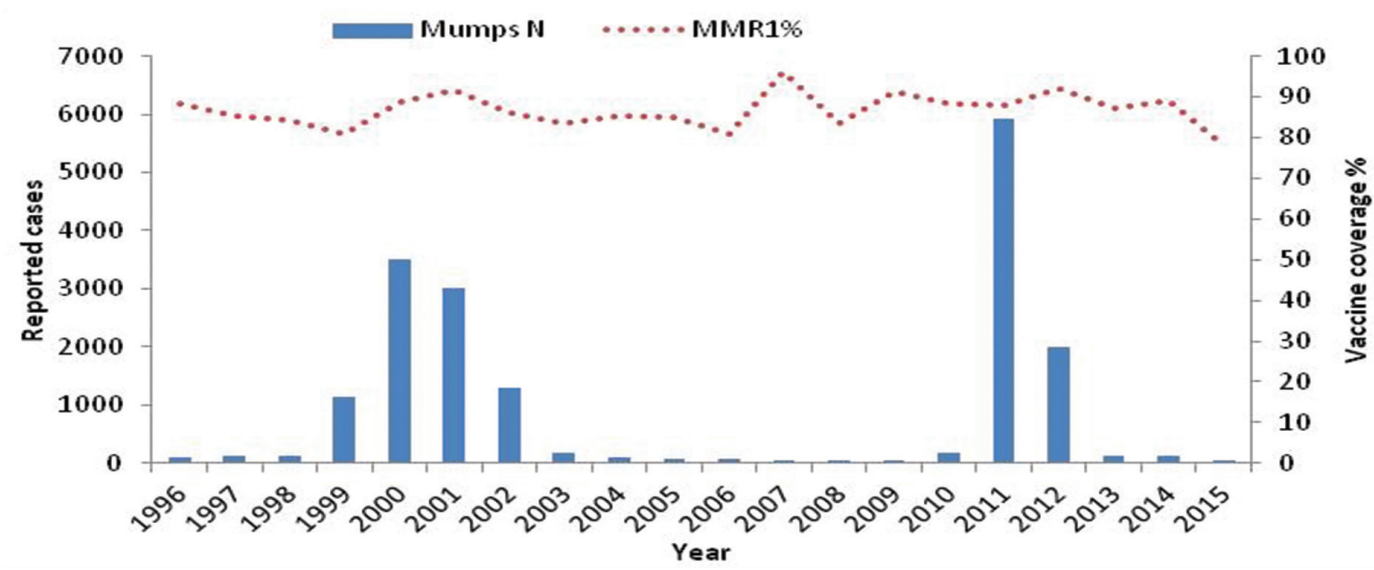

Fig. 2 Annual reported cases of mumps and MMR1 coverage, Federation Bosnia and Herzegovina 1996-2015. 


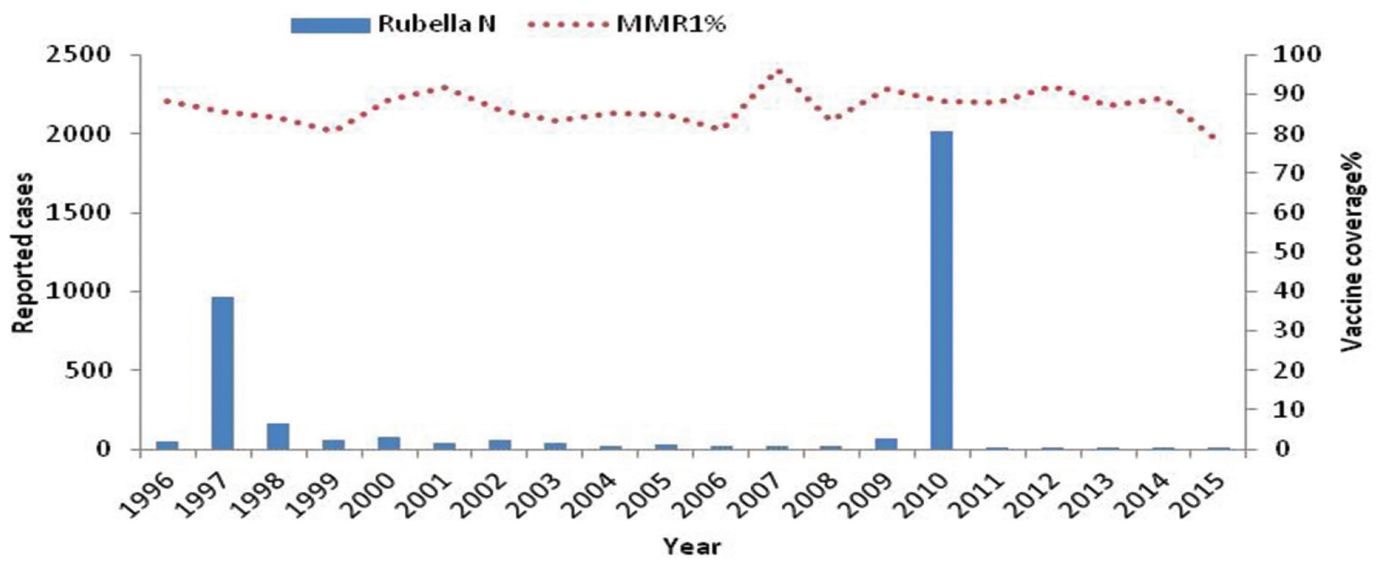

Fig. 3 Annual reported cases of rubella and MMR1 coverage, Federation Bosnia and Herzegovina 1996-2015.

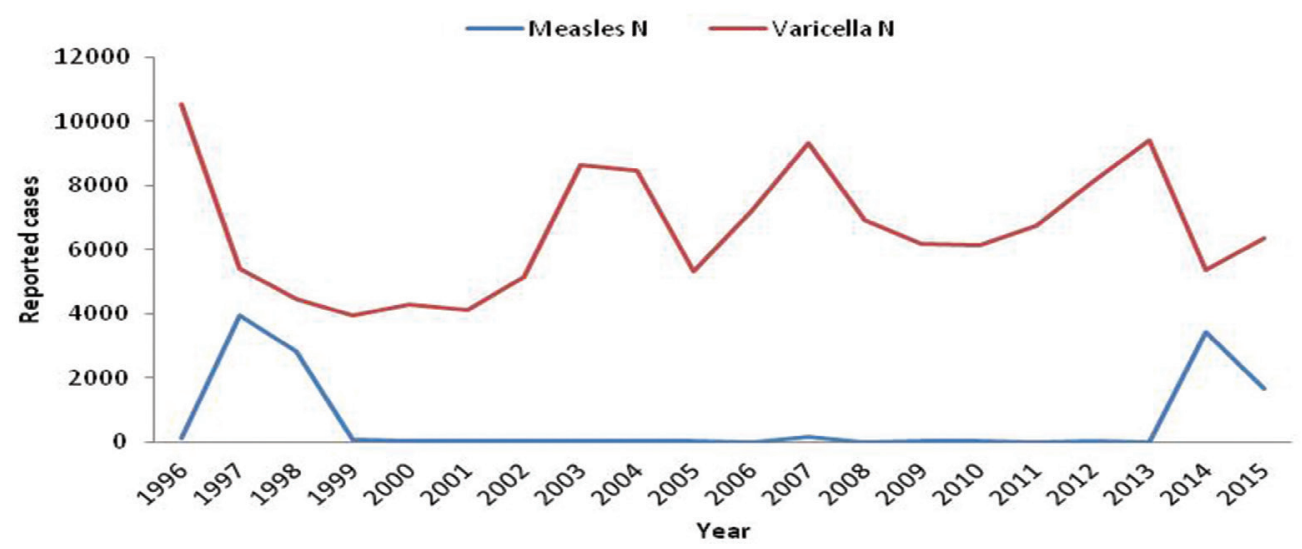

Fig. 4 Annual reported cases of measles and varicella, Federation Bosnia and Herzegovina 1996-2015.

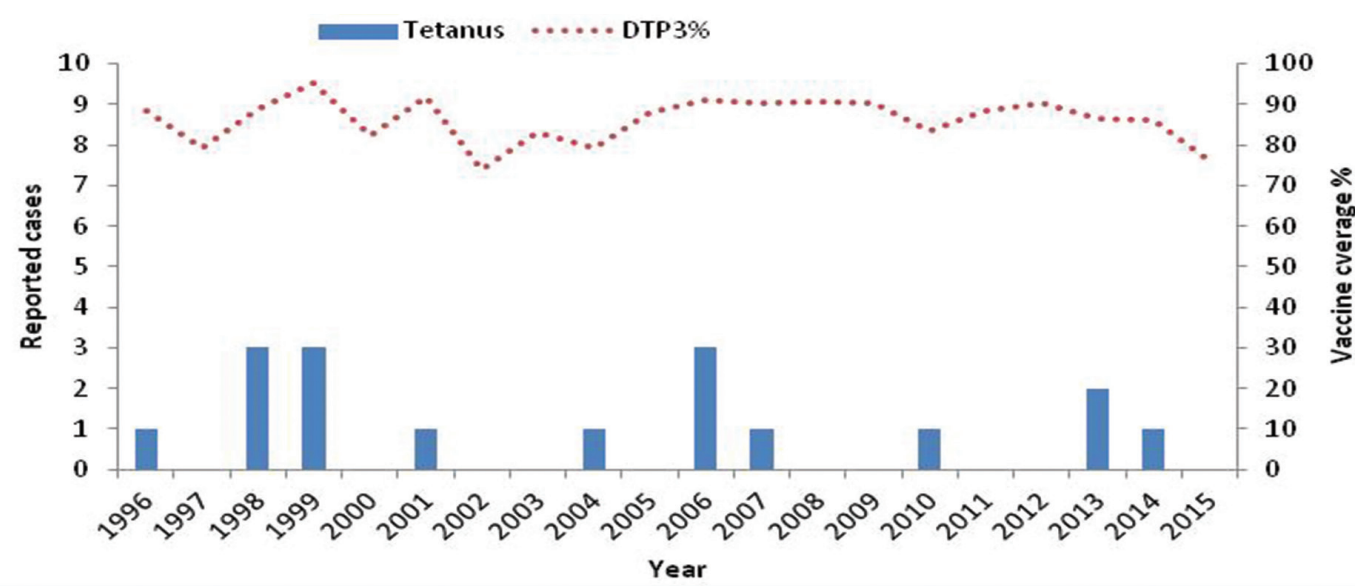

Fig. 5 Annual reported cases of tetanus and DTP3 coverage, Federation Bosnia and Herzegovina 1996-2015. 


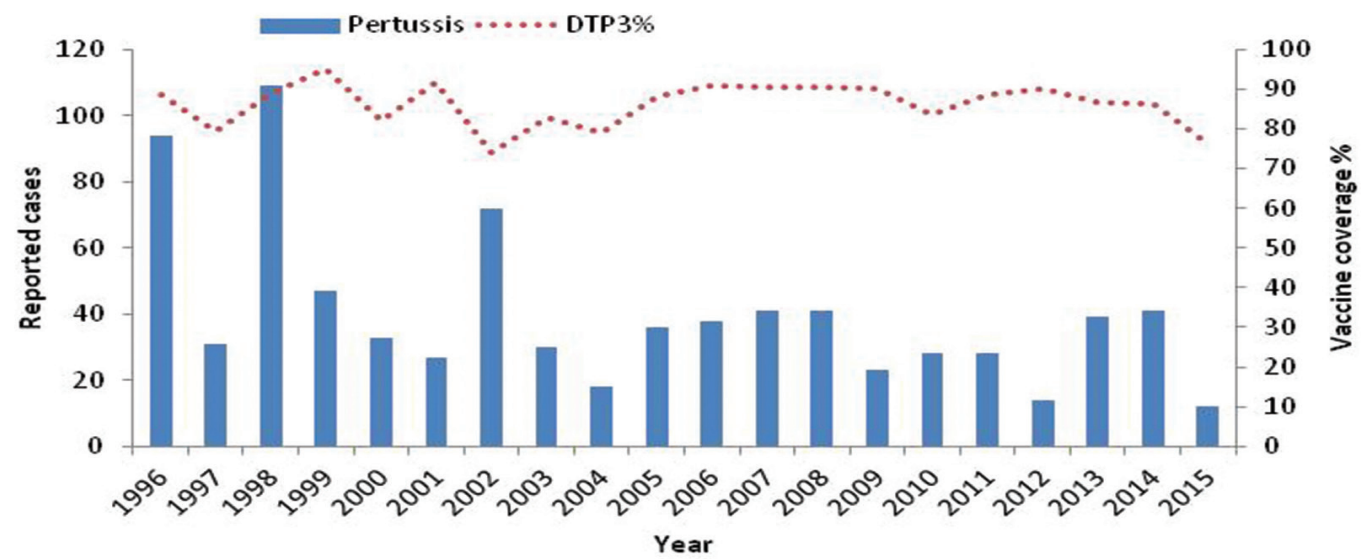

Fig. 6 Annual reported cases of pertussis and DTP3 coverage, Federation Bosnia and Herzegovina 1996-2015.

of pertussis were reported during the last 20 years. During the period 2000-2015, among 568 registered cases, $86.2 \%$ (490 cases) were under five years old.

\section{Historical comparisons of morbidity and mortality for vaccine-preventable diseases}

DTP vaccine (combined vaccine) was introduced in the immunization program in 1961, as was the vaccination against poliomyelitis. When we compare the average number of cases and deaths registered during the period 1951-1961 (before the immunization program was established or satisfactory vaccination coverage was achieved in the People's Republic of BA, and in the Federation of BA 1996-2015), there was clear evidence of the reduction of burden of vaccine-preventable diseases (Table 2). Diphtheria and poliomy- elitis have been eliminated, and tetanus and pertussis have been significantly reduced.

\section{Discussion}

The key issues to be considered before deciding to introduce a vaccine can be grouped into three areas: first area relates to the disease that the vaccine in question targets, second area to the vaccine, and third area to the capacity of the immunization program and underlying health system (16). Disease is considered to be serious for individual if: it can cause death, serious complications or permanent invalidity, and diagnosis and appropriate treatment do not provide adequate scope for control of disease (17). A disease may be serious for a society based on one or more of the following: it has significant annual rates of incidence or mortality, it can spread rapidly, it can cause a large-scale epidemic, it can lead to social dis-

Table 2 Historical comparisons of morbidity and mortality for diphtheria, tetanus, pertussis and poliomyelitis, Bosnia and Herzegovina/Federation of Bosnia and Herzegovina

\begin{tabular}{lllll}
\hline $\begin{array}{l}\text { Vaccine } \\
\text { preventable } \\
\text { diseases }\end{array}$ & $\begin{array}{l}\text { Average number of cases } \\
\text { per year (peak cases) } \\
1951-1961\end{array}$ & $\begin{array}{l}\text { Average number of deaths } \\
\text { per year (peak cases) } \\
1951-1961\end{array}$ & $\begin{array}{l}\text { Average number of } \\
\text { cases per year (peak } \\
\text { cases) 1996-2015 }\end{array}$ & $\begin{array}{l}\text { Average number of } \\
\text { deaths per year (peak } \\
\text { cases) 1996-2015 }\end{array}$ \\
\hline Diphtheria & $632(753)$ & $32(52)$ & - & - \\
\hline Tetanus & $67(83)$ & $25(39)$ & $0.5(3)$ & - \\
\hline Pertussis & $5149(8662)$ & $72(306)$ & $40(109)$ & - \\
\hline Poliomyelitis & $65(301)$ & $3(17)$ & - & - \\
\hline
\end{tabular}


ruption and there are no adequate alternative means for protecting against it (17).

Before a vaccine is licensed for use, its safety and efficacy must be proven. Randomized double-blind placebo-controlled trials are ideally used to prove the efficacy of vaccines. Such trials demonstrate clinical protection, but also may demonstrate correlates of protection, measuring serum antibody as a surrogate of clinical protection (18). After licensure, the vaccine and the vaccination program must also be monitored in an adequate way to provide evidence of its effectiveness, usually by assessing coverage and measuring disease incidence (18). Effectiveness summarizes the extent to which vaccination is able to prevent disease and symptoms. At the same time, safety is measured by a post-marketing assessment of adverse events following immunization. The efficacy of vaccines in clinical use can be determined by a variety of means including screening, outbreak investigations, secondary attack rates in families or clusters, vaccine coverage assessments, and case-control studies (19).

Through community immunity, or herd immunity, some non-immune people will be indirectly protected by the presence of immune persons, and transmission should stop in a population prior to the infection of all susceptible individuals. The approximate basic reproduction number, a standard measure of the transmissibility of an infection, for measles is $12-18$, and crude herd immunity thresholds are 92-94. Diphtheria has the basic reproduction number of 6-7 and crude herd immunity thresholds of 83-85 $(20,21)$.

Diphtheria is a disease that is presently under control in the Federation of BA, but events of diphtheria in Eastern Europe in 1990's have shown that the disease burden associated with diphtheria can increase rapidly if the vaccination rate falls below a thresholds level. Estimated global DTP3 coverage among children under ones year old in 2014 was $86 \%$, ranging from $77 \%$ in the $\mathrm{WHO}$
African Region to $96 \%$ in the Western Pacific Region, and representing 115.2 million vaccinated children (22).

Despite the undertaken efforts on the issue of measles and rubella elimination in Europe by 2015 , the number of measles cases has been increasing in numerous European countries in the recent years $(23,24,25)$. The number of WHO member states with $\geq 90 \%$ vaccine coverage against measles increased from $84(44 \%)$ in 2000 to $122(63 \%)$ in 2014 (26). During this period, measles vaccination prevented an estimated 17,1 million deaths (26). Continued measles virus circulation in several European countries, as well as in BA, reflects low vaccination coverage in particular populations and the associated accumulation of susceptible persons. In the 2010/12 mumps outbreak in Federation of BA, $15,3 \%$ of fully vaccinated persons had mumps. According to CDC's The Pink Book, two dose mumps vaccine effectiveness is $88 \%$ (66 to $95 \%$ ) (27).

Programs using pertussis vaccines have been highly successful in preventing severe pertussis in infants worldwide. There is a lot of discussion regarding the vaccine against pertussis. Evidence of waning vaccine-derived protection and a shift in the age distribution of the pertussis disease incidence is documented (28). There is also increasing evidence that even the majority of European countries have now switched to aP vaccine as a means of decreasing the reactogenicity, that efficacy and duration of protection between the $\mathrm{aP}$ and $\mathrm{wP}$ vaccine types differ, in a favor of wP vaccine $(28,29)$. In 2012, among countries of the European Union, the notification rate of pertussis cases was more than twice as high as in previous years. The most affected age group was 5-14 year-olds (30). Comparing vaccine coverage and incidence of measles and pertussis in the Federation of $\mathrm{BA}$, we believe that much of pertussis cases go unrecognized and unreported. 
Poliomyelitis is nearing eradication. This Polio Eradication \& Endgame Strategic Plan 2013-2018, outlines the strategic approach to the eradication of all remaining polio disease (wild and vaccine-related polioviruses) (31). Withdrawal of all OPV is planned for 2019-2020, beginning with the withdrawal of the type 2 component of trivalent oral polio vaccine (tOPV) in April 2016. Among the countries in $\mathrm{EU}$ region, $\mathrm{BA}$ is considered to be at high risk of polio transmission in 2015 , together with Romania and Ukraine, due to suboptimal vaccine coverage (32).

The Global Vaccine Action Plan 2011-2020, endorsed by the 194 Member States of the World Health Assembly in May 2012, sets goals for the decade: to achieve a world free of poliomyelitis, meet vaccination coverage targets in every region, country and community, exceed the Millennium Development Goal 4 target for reducing child mortality, meet global and regional elimination targets, develop and introduce new and improved vaccines and technologies (33). Major identified challenges and strategic plans for development of the current surveillance system are: improvement and modernization of surveillance information systems to arrive at integrated electronic systems (to enable individual case-based reporting at federal level), insufficient and under-trained human resources and the need for public health workforce capacity building, inter-sectorial collaboration, improvement of integration of laboratory networks and increase capabilities of labs, adjustment of state legislation to the EU requirements and effective country data reporting to The European Surveillance System (TESSy) database (34).

Developing a computerized immunization registry to replace the existing paperbased registry is critical for comprehensively assessing vaccine coverage. A communication strategy, as a critical issue in vaccine acceptance, should be an integral part of the immunization program. Impacts of vaccination against tuberculosis, invasive Hib disease and hepatitis B are not covered in this study and it should be described in a separate analysis.

\section{Conclusion}

Despite impressive achievements in vaccinepreventable diseases control, continued trust and investments in the immunization program in the Federation of BA are essential. A communication strategy should be an integral part of the immunization program.

Conflict of interest: The authors declare that they have no conflict of interest.

Acknowledgement: The authors thank Azemina Bešić (Epidemiology service stuff) for her contribution in data collection process.

Authors' contributions: Conception and design: SM; Acquisition, analysis and interpretation of data: SM and MM; Drafting the article: SM; Revising the article critically for intellectual content: MM; Approved final version of the manuscript: SM and MM.

\section{References}

1. WHO, UNICEF, World Bank. State of the world's vaccines and immunization, 3rd ed. Geneva, World Health Organization, 2009.

2. Petrović R. Immunizations.2nd revised and expended edition [In Serbo-Croatian]. Medicinska knjiga Beograd-Zagreb, 1986. pp 32.

3. Anonymous. Official Gazette of the Federal People's Republic of Yugoslavia [In Serbo-Croatian]. 1948;37.

4. Anonymous. Official Gazette of the Federal People's Republic of Yugoslavia [In Serbo-Croatian]. $1948 ; 47$.

5. Anonymous. Official Gazette of the Federal People's Republic of Yugoslavia [In Serbo-Croatian]. 1960;11.

6. Anonymous. Official Gazette of the Federal People's Republic of Yugoslavia [In Serbo-Croatian]. 1960;30.

7. World Health Organization. Global routine vaccination coverage, 2014. Wkly Epidemiol Rec. 2015; 90(46):617-23.

8. Anonymous. Official Gazette of the Socialist Republic of Bosnia and Herzegovina [In Serbo-Croatian]. 1969;33. 
9. Anonymous. Official Gazette of the Socialist Republic of Bosnia and Herzegovina [In Serbo-Croatian]. 1980;34.

10. Anonymous. Official Gazette of the Federation of Bosnia and Herzegovina [In Croatian]. 2001;21.

11. Ministry of Foreign Affairs Bosnia and Herzegovina. [homepage on the Internet]. Constitution Bosnia and Herzegovina. [; cited 2016 Aug 9]. Available from: http://www.mvp.gov.ba/dobro_dosli_u_bih/ drzavno_uredjenje/ustav_bih/?id=261.

13. Anonymous. Official Gazette of the Federation of Bosnia and Herzegovina [In Croatian]. 2005;29.

14. Anonymous. Official Gazette of the Federation of Bosnia and Herzegovina [In Croatian]. 2012;101.

15. Anonymous. Official Gazette of the Federation of Bosnia and Herzegovina [In Croatian]. 2007;22.

16. Hukic M, Hajdarpasic A, Ravlija J, Ler Z, Baljic $\mathrm{R}$, Dedeic Ljubovic A, et al. Mumps outbreak in the Federation of Bosnia and Herzegovina with large cohorts of susceptibles and genetically diverse strains of genotype G, Bosnia and Herzegovina, December 2010 to September 2012. Euro Surveill. 2014;19(33):pii=20879.

17. World Health Organization. Principles and considerations for adding a vaccine to a national immunization programme: from decision to implementation and monitoring. Geneva (Switzerland): World Health Organization, 2014.

18. Houweling H1, Verweij M, Ruitenberg EJ. National Immunisation Programme Review Committee of the Health Council of the Netherlands. Criteria for inclusion of vaccinations in public programmes. Vaccine. 2010;28(17):2924-31.

19. Orenstein WA, Bernier RH, Hinman AR. Assessing vaccine efficacy in the field. Further observations. Epidemiol Rev. 1988;10:212-41.

20. Orenstein WA, Bernier RH, Dondero TJ, Hinman AR, Marks JS, Bart KJ, et al. Field evaluation of vaccine efficacy. Bull World Health Organ. 1985;63(6):1055-68.

21. Fine PEM, Mulholland K. Community immunity. In: Plotkin SA, Orenstein WA, Offit PA, editors. Vaccines 6th edition. Philadelphia: WB Saunders; 2013, 3425-51.

22. Fine PE. Herd immunity: history, theory, practice. Epidemiol Rev. 1993;15:265-302.

23. World Health Organization. Global routine vaccination coverage, 2014. Wkly Epidemiol Rec. 2015;90(46):617-23.
24. World Health Organization. Eliminating measles and rubella - Framework for the verification process in the WHO European Region. Copenhagen: WHO Regional Office for Europe; 2012.

25. Mankertz A, Mulders MN, Shulga S, Kremer JR, Brown KE, Santibanez S, et al. Molecular genotyping and epidemiology of measles virus transmission in the World Health Organization European Region, 2007-2009. J Infect Dis. 2011;204 (Suppl 1):S335-42.

26. Santibanez S, Prosenc K, Lohr D, Pfaff G, Jordan Markocic O, Mankertz A. Measles virus spread initiated at international mass gatherings in Europe, 2011. Euro Surveill. 2014;19(35):20891.

27. World Health Organization. Progress towards regional measles elimination, worldwide, 2000 2014. Wkly Epidemiol Rec. 2015;90(46):617-23.

28. Centers for Disease Control and Prevention. Epidemiology and Prevention of Vaccine-Preventable Diseases. Hamborsky J, Kroger A, Wolfe S, eds. 13th ed. Washington D.C. Public Health Foundation, 2015, pp 247-60.

29. Gambhir M, Clark TA, Cauchemez S, Tartof SY, Swerdlow DL, Ferguson NM. A change in vaccine efficacy and duration of protection explains recent rises in pertussis incidence in the United States. PLoS Comput Biol. 2015;11(4):e1004138.

30. World Health Organization. Pertussis vaccines: WHO position paper - August 2015. Wkly Epidemiol Rec. 2015;90(36):433-60.

31. European Centre for Disease Prevention and Control. Annual epidemiological report 2014 - vaccinepreventable diseases. Stockholm: ECDC; 2014.

32. World Health Organization. Polio Eradication \& Endgame Strategic Plan 2013-2018. Geneva (Switzerland): World Health Organization; 2013.

33. European Centre for Disease Prevention and Control. Outbreak of vaccine-derived poliovirus type 1 (cVDPV1) in Ukraine, August 2015 - 2 September, Stockholm, 2015.

34. World Health Organization. Global vaccine action plan 2011-2020. Geneva (Switzerland): World Health Organization; 2013.

35. European Centre for Disease Prevention and Control. Meeting report: ECDC Regional meeting with the EU enlargement countries: Perspectives on participation in the European network for communicable disease surveillance and control 5-6 September 2013, Sarajevo, Bosnia and Herzegovina. 